\title{
Faculty and Student Perceptions of Project-Enhanced Learning in Early En- gineering Education: Barriers, Benefits, and Breakthroughs
}

\section{Prof. M. Razi Nalim P.E., Indiana University Purdue University, Indianapolis}

Prof. Razi Nalim has over 25 years of practical and analytical experience in combustion, explosions, engines, and non-steady flow related areas in industry, academia, and government. His career began in internal-combustion engine emissions control, cogeneration systems, and engine testing. After his doctorate, Dr. Nalim went to NASA Glenn Research Center to study unsteady flow devices for propulsion and power. He has received several patents and published over a hundred technical papers related to pulsed flow, combustion systems, and biological fluid flow. He established the Combustion \& Propulsion Research Laboratory in Indianapolis and a pioneering Purdue University research program in wave rotor constant-volume combustion in collaboration with engine industry. He was twice awarded the Abraham Max Distinguished Professorship, as well as the Frank Burley Distinguished Professorship - the highest honors of the Purdue University School of Engineering and Technology for research and service accomplishments, respectively. He has consulting experience related to injury and patent litigation, emissions testing, combustion, and design of jets, and has given invited lectures at major institutions worldwide. He served overseas as a Fulbright Senior Scholar and is an Associate Fellow of the American Institute of Aeronautics \& Astronautics.

\section{Dr. Manikanda K Rajagopal, Indiana University - Purdue University Indianapolis}

Manikanda Rajagopal earned his Bachelor degree in Mechanical Engineering from Thiagarajar College of Engineering, India in 2002. He obtained his Ph.D in Mechanical Engineering from IIT Madras, India in 2009. Subsequently, he worked at General Motors Technical Center for 2 years with specialization in external aerodynamics . Later, he joined as Postdoctoral Research Associate at Combustion and Propulsion Research Laboratory, Indiana University - Purdue University Indianapolis, USA. His research interests includes Combustion, Propulsion, Gas dynamics, CFD and Engineering education.

\section{Dr. Robert J Helfenbein, Indiana University-IUPUI, School of Education}

Rob Helfenbein is Associate Professor of Curriculum Studies at Indiana University-IUPUI and Director of the Center for Urban and Multicultural Education (CUME). He earned his Ph.D. and B.A. from the University of North Carolina at Chapel Hill. Dr. Helfenbein offers courses in Teaching Secondary Social Studies and graduate level courses in curriculum theory, qualitative research methods, social foundations, and urban education. Dr. Helfenbein has published and edited numerous research articles and book chapters about contemporary education analysis in urban contexts in journal such as Curriculum Inquiry, the Journal of Curriculum Theorizing, Educational Studies, The Urban Review, the Review of Education, Pedagogy, and Cultural Studies, and co-edited the volumes Unsettling Beliefs: Teaching Theory to Teachers (2008) and Ethics and International Curriculum Work: The Challenges of Culture and Context (2012). In 2008, Dr. Helfenbein served as the Section Chair for Critical Perspectives and Practices of AERA Division B-Curriculum Studies followed by serving as overall Program Chair for Division B in 2009 and was nominated into the Professors of Curriculum at AERA 2011. He is currently Editor of the Journal of Curriculum Theorizing and President of the Foundation for Curriculum Theory. 


\title{
Faculty and Student Perceptions of Project-Enhanced Learning in Early Engineering Education: Barriers, Benefits, and Breakthroughs
}

\begin{abstract}
The application of problem-based learning (PBL) to undergraduate engineering education has emerged as an area of research interest over the past few decades. A related form of active learning is project-enhanced learning (PEL), intended to support integrative thinking and student motivation. PEL is specifically designed as a supplement to, but not a replacement for, traditional teaching methods in early engineering science courses. Data regarding perceived benefits and barriers to PEL as an intervention for improved student learning were collected from instructors engaged in PEL, and were examined using extended-term mixed-method research design (ETMM). ETMM enables researchers to remain attentive to contextual factors shaping program implementation and to changes in implementation over time. The case study included interviews with faculty, and survey instruments as part of the multiple data-point strategy. Among the findings, instructors adding PEL to their instructional strategies expressed satisfaction with improved student motivation, interaction, and socialization, which may help with student success and retention in engineering. Some instructors expressed concern about losing focus on the challenging analytical course topics, but those who attempted PEL were able to achieve appropriate balance by designing project tasks to align well with the topics and by limiting non-aligned project activity. In some cases, instructors who initially resisted adopting PEL changed to a favorable disposition after interacting with students and faculty who were favorable. However, a small number of instructors responded to the survey with a strong negative view of PEL.
\end{abstract}

\section{Introduction}

This paper represents the findings of the NSF-funded study "Implementation, Dissemination, Barrier Identification and Faculty Training for Project-Enhanced Learning in Gateway Engineering Courses" and highlights faculty perceptions of the use of Project-Enhanced Learning (PEL) strategies specifically in sophomore and junior-level engineering science courses. PEL is defined as an integrated project within a traditional lecture-based course that can be implemented in a gradual and transferable way and across multiple sections and instructors ${ }^{1}$. PBL or other active learning approaches are uncommon in the most challenging mid-program engineering courses, and evidence remains of continued attrition of engineering students in these courses. This suggests a continuing need to experiment with approaches that are not only effective, but are manageable and sustainable for typical instructors. As many undergraduates perform poorly in early engineering science courses that are primarily lecture-based, attention to pedagogical innovation may present an opportunity for increased retention. Additionally, surveys, and classroom assessments indicate that many students completing these courses did not really understand the fundamentals, even if they could apply the 'formulae'. 
The contributors in this project have designed and implemented project experiences in three different 'gateway' engineering science courses, based on initial experiences in a course on Thermodynamics in the mechanical engineering curriculum. We refer to the first courses in the engineering major as 'gateway' engineering courses, specifically courses in engineering sciences and analysis taken in the sophomore and junior years, in contrast to first-year and senior-year design-oriented courses. In Fall 2011, PEL was introduced in two other courses: Probabilistic Methods In Electrical And Computer Engineering, and Dynamics in the mechanical engineering curriculum $^{2}$. One or two major projects based on authentic systems, objects, or activities are designed by the instructors and assigned to apply key course topics. The goals include increasing student motivation and retention, providing realistic application of abstract concepts, long-term learning retention, and training of novice instructors adopting active learning approaches. Student teamwork, increased communication with engineering faculty, and professionalism were also emphasized. Significant findings include faculty perceptions of both the value of and barriers to implementing a PEL component in gateway engineering courses and an underlying understanding of the need for increased student engagement in the engineering curriculum.

\section{Literature Review}

For most college majors, the first year is the most critical for persistence in college. Tinto ${ }^{3}$ observed that almost one-half of students entering two-year colleges and more than one-fourth of students entering four-year collegiate institutions leave at the end of their first year. However, in the decade ending in 2010, attrition in the first year fell $3 \%$ at a sample of public universities, while attrition in later years rose $1.5 \%$. Three-fifths of attrition occurs after the first year ${ }^{4}$. For challenging engineering programs, an even higher first-year attrition rate may be a predictable feature of student experimentation. Many universities now have thoughtfully redesigned firstyear programs to encourage retention. More worrying, a significant fraction of students who decide at that point to persist in engineering, nonetheless leave engineering in the middle years of college. Faculty classroom behaviors in general and active learning in particular (of which PEL may be considered a form) may constitute an empirically reliable source of influence on social integration, subsequent institutional commitment, and departure decisions ${ }^{5}$. The learning styles of diverse students may be better invoked by a wider range of instructional strategies ${ }^{6}$, if well integrated.

A large body of research affirms that active learning enhances student knowledge and understanding of course content ${ }^{6-9}$. Moreover, students who frequently encounter active learning in their courses perceive themselves gaining knowledge and understanding from their course work. As a consequence of this self-efficacy, such students may be more likely to view their collegiate experience as personally rewarding ${ }^{10}$. Students who frequently experience active learning in their classes may also have more time available for participation in collegiate social communities because they feel that they are able to spend less time on course preparation and studying for examinations. Through multiple effects, active learning course practices may directly influence social integration and indirectly affect subsequent institutional commitment and student departure decisions. Tinto ${ }^{3}$ presents findings on the role of active learning in influencing student persistence/departure decisions. 
Research conducted by the Southeastern University and College Coalition for Engineering Education (SUCCEED) provide a unique snapshot of engineering education at a transitional moment in its history ${ }^{11}$. The major component of this study is the design and implementation of a faculty development program. The objectives of this program were: (1) to promote faculty adoption of non-traditional instructional methods and materials that have been proven effective by classroom research studies and (2) to improve institutional support for teaching at each of the eight SUCCEED campuses. The study finds that the percentage of responders giving required team assignments vary from a low of $35 \%$ at one institution to a high of $72 \%$. Assistant professors are more likely to do so than associate or full professors. Female professors are more likely than male professors to use in-class group activities and the internet in their teaching, and the assistant professors and female professors are more likely to believe that teaching is devalued in the faculty reward system. In short, while there is general agreement that active learning approaches such as PEL have positive outcomes for students but there is great variance in faculty perceptions of non-traditional instructional strategies and the benefit/rewards for increased faculty implementation.

Conventional teaching methods for engineering courses continue to be lecture-based and necessarily emphasize deductive learning in the engineering science courses that students encounter early in their major. These courses expect students to learn and apply in a semester, engineering principles that have been axiomatized over decades or centuries. The application of problem-based learning (PBL) to undergraduate engineering education has emerged as an area of research interest over the past few decades, although it does not appear to be the dominant pedagogy for most engineering programs. Educational studies often use the lecture as the default style to compare alternative methods to, such as PBL or active learning ${ }^{12-14}$. An evidence-based comparative study examining the effectiveness of PBL versus lecture-based learning in an introductory engineering course revealed that students retained more knowledge when instructors used a PBL approach ${ }^{12}$. Research in engineering education has shown that building a sense of community and hands-on learning (which is often seen in PBL) contribute to increased student retention and motivation ${ }^{15,16}$. In many instances PBL is used as a partial strategy or in addition to traditional curriculum in engineering courses ${ }^{17-20}$.

Projects are universally the 'modus operandi' of engineering practice. Projects are typically a component of engineering design courses, which are usually separate from engineering science and are more likely though not all at the upper level. As examples of research on project work, Dym et $\mathrm{al}^{21}$ present project-based learning as the favored model for teaching design, while Frank et $\mathrm{al}^{22}$ present a freshman year introductory engineering course based on project work. PBL and project work share some similarities such as being multi-disciplinary, collaborative, and selfdirected, but the two approaches differ slightly in their focus and method of implementation ${ }^{24}$. In PBL, the teacher is seen as a facilitator in the process, rather than a lecturer. The process is selfdirected and the students' goal is to refine the problems ${ }^{25}$. PBL is geared toward acquiring knowledge, whereas project-based learning is typically directed toward applying knowledge. Project-based learning tends to be more focused on real-world applications and attempts to mimic professional work. Project work tends to take a longer period of time than the tasks in PBL because the projects are more complex and closer to professional reality. Students also tend to produce a concrete product in project work (Table 1). 
The suitability of problem-based versus project-based learning for engineering education was compared by Mills \& Treagust ${ }^{24}$. In their review of university engineering programs, they concluded that a hybrid approach in which students took more traditionally lecture-based courses covering the fundamentals of engineering combined with project-based components was best for preparing students for the workforce and would be more familiar to instructors than problembased methods. They also relate the concern of engineering faculty that problem- and projectbased learning may be problematic in the hierarchical (rather than encyclopedic) knowledge structure of engineering. Faculty may worry that over reliance on such methods may cause students to 'miss out' on a key concept or principle that are not applied in the selected project. Perrenet et al. ${ }^{20}$ reviewed the literature and compared programs that implemented PBL as a partial strategy. They concluded that some direct instruction of core concepts is necessary, and that PBL and project work have advantages in motivating students as well as being more cognitively engaging than conventional instruction.

Barroso and Morgan ${ }^{25}$ define project-enhanced learning as the implementation of projects in engineering courses that utilize open-ended problems and allow abundant opportunities for students to make decisions in the design and assessment of their work. They distinguish this from project-added implementation, in which projects are viewed as an additional lengthy homework assignment and have well-structured problems with clearly defined solutions and outcomes (Table 1).

table I. Focus And Components Of Selected Teaching Methods ${ }^{25}$

\begin{tabular}{|c|c|c|c|}
\hline $\begin{array}{l}\text { Problem-based } \\
\text { learning (PBL) }\end{array}$ & $\begin{array}{l}\text { Project-based } \\
\text { learning }\end{array}$ & $\begin{array}{l}\text { Project-enhanced } \\
\text { learning (PEL) }\end{array}$ & $\begin{array}{l}\text { Project-added } \\
\text { implementation }\end{array}$ \\
\hline $\begin{array}{l}\text { - Acquisition of } \\
\text { knowledge } \\
\text { - Students solve real- } \\
\text { life problems as a } \\
\text { team } \\
\text { - Teacher is seen as a } \\
\text { facilitator in the } \\
\text { process } \\
\text { - Students' goal is to } \\
\text { refine the problems }\end{array}$ & $\begin{array}{l}\text { - Application of } \\
\text { knowledge } \\
\text { - Students create } \\
\text { projects with real- } \\
\text { world applications } \\
\text { - Mimics professional } \\
\text { work } \\
\text { - Projects take an } \\
\text { extended period of } \\
\text { time (up to several } \\
\text { months) }\end{array}$ & $\begin{array}{l}\text { - A project is } \\
\text { integrated with a } \\
\text { traditional lecture- } \\
\text { based course } \\
\text { - Can be } \\
\text { implemented in a } \\
\text { gradual and } \\
\text { transferable way } \\
\text { over time and } \\
\text { among multiple } \\
\text { sections and } \\
\text { instructors }\end{array}$ & $\begin{array}{l}\text { - Projects are an added } \\
\text { course component that can } \\
\text { be seen as a larger and } \\
\text { more complex homework } \\
\text { problem } \\
\text { - Well-structured problems } \\
\text { with clear instructions for } \\
\text { completion } \\
\text { - Well-defined project } \\
\text { outcome }\end{array}$ \\
\hline
\end{tabular}

Krishnan and Nalim ${ }^{1}$ offer their own unique approach of project-enhanced learning (PEL), which integrates a major project with a traditional lecture series in courses on engineering science and analysis (rather than design). The project integrates knowledge acquisition with application. In their conceptualization of PEL, core topics are introduced early in a course in relation to a project so that students anticipate what they will learn in lecture. This model is designed for implementation at the early stages of an engineering student's coursework, such as the sophomore year when students take many gateway courses, rather than waiting until content is mastered to begin project work. PEL introduces core concepts early in an engineering program with the integration of a term-long project, and the learning is thought to be transferred over time 
with this method. The current study adopts this interpretation, contrasting PEL with the more student-created project-based learning, but not making it sharply distinct from project-added implementation. The accommodation of PEL within a traditional lecture-based setting is deliberately intended to ease this intervention into courses where traditional methods are most entrenched. Some benefits of this model have been identified, such as increasing the motivation of students, but more research is needed on PEL. Krishnan and Nalim recommend future studies looking at the longitudinal impact of PEL on student retention in engineering programs, student performance, and students' professional outcomes.

\section{Research Design}

The guiding research approach for the project follows the Extended-Term Mixed-Method (ETMM) design ${ }^{26}$. Workshop observation, qualitative interviews, and a constant-comparative analysis ${ }^{27}$ were utilized in the research design. The research project follows a formative case study design to explore the implementation of PEL in gateway engineering courses. The research team has been conducting the evaluation, consisting of process observations, qualitative data collection, and an extensive survey. The evaluation results, considered existing data that the research team then used to inform the ongoing design of the proposed research project. Participants in the case study included instructors who teach gateway engineering courses at three research-intensive urban universities located in three different American states. These were Indiana University - Purdue University Indianapolis (IUPUI), and University of Illinois Chicago.

One group of participants all agreed to attempt PEL, and some had begun implementation of PEL in their courses. The team conducted interviews focused on instructional planning and reflections on PEL as a pedagogical strategy. In addition, these instructors were recruited to participate in a series of professional development activities and focus group discussions occurring at various points throughout the ongoing project. The participants in interviews and focus group discussion did not include instructors who declined to attempt PEL.

All individual participants in this group were contacted initially by a member of the research team via email or a phone call, and face-to-face during the interview phase. Consent statements were collected for participation in the research and evaluation following all appropriate requirements for human subjects research.

A larger group of participants $(n=18)$ were surveyed at the end of the first year of the project. This group included instructors who agreed or declined to attempt PEL, and those not exposed to PEL at the time of the survey.

\section{A. Research Team}

The research team was all involved in literature review, data collection, and preliminary data analysis. The guiding approach for the processes and products of the project follows the Extended-Term Mixed-Method (ETMM) design ${ }^{26}$. This design includes five inter-related principles: (a) developing a long-term time-line, (b) using theory and data to inform decisions, (c) paying attention to formative and summative components of the study, (d) creating sharply 
focused causal questions regarding impact of the program, and (e) using a variety of quantitative and qualitative evidence to support claims.

\section{B. Research Questions}

1. How are instructors implementing (or not) PEL in their classrooms?

2. How does the implementation of PEL in gateway engineering classrooms follow "best practice" as identified by the research?

3. How supported (by all stakeholders) do instructors feel during the PEL implementation process?

4. What are the challenges to implementing PEL in engineering classrooms?

\section{Methods and Instruments}

1) Observations. Using qualitative inquiry and ethnographic methods ${ }^{28,29}$, team members have conducted a series of observations of PEL instruction, professional development, and coaching. An ethnographic approach is appropriate for building a detailed account of how the implementation process unfolds within the context of a classroom and school, and illuminate some of the strengths and challenges of individual instructors as they move through the implementation process.

2) Interviews. Team members have interviewed PEL-involved instructors $(\mathrm{n}=5)$ about support structures within the IUPUI School of Engineering \& Technology and about their perceptions of how the implementation process is going overall. Sample interview probes are: "What kinds of support have been provided during the implementation process?"; "How have students responded to PEL?"; and "How has PEL affected student learning?"

3) Document review. The research team is collecting lesson and unit plans including entry documents and other PEL-related planning materials, assessment rubrics, samples of student work, and teacher reflections in order to understand PEL implementation processes and evaluate the objectives. These data were analyzed using content analysis ${ }^{30}$.

4) Survey. Implementation surveys were disseminated to all engineering course instructors of the three participating universities, at the end of the first year of the project. These asked participants a series of questions about their implementation of PEL in their classrooms as well as some of the challenges they have experienced in implementation. Responses included instructors from two universities involved in the project $(n=18)$. Results were compared to the existing data from the PEL evaluation to see how and in what ways teachers have followed through with their plans to implement PEL in their classrooms.

No inducements were offered for responding to the survey. The authors acknowledge what may be a significant non-response bias in the survey data. Those who did not respond may, on average, hold significantly more negative views of PEL than those who responded. However, the positive and negative view did provide a spectrum of opinion, and significant insight into faculty-perceived benefits and barriers to PEL. 


\section{Qualitative Analysis}

The constant-comparative method ${ }^{31}$ was employed to allow researchers to use the initial results of one method to extend or clarify the results from another method. As data sets from each of the various sources are obtained, they were initially coded to determine common patterns within the data and develop overarching themes. Throughout subsequent data collection activities, researchers built upon existing data to inform the collection process. Additionally, data previously collected and analyzed was shared with stakeholders including participants for member checking in order to solicit feedback on analyses to date.

\section{Findings}

\section{A. How are instructors implementing (or not) PEL in their classrooms?}

Implementation of PEL and other active learning strategies varies among the engineering faculty participating in this study. $80 \%$ of faculty described their primary teaching method as lecture although considerable variation was reported in relation to group assignments, use of hands-on activities, and allowing for student choice in class assignments. Differences in approach relate to the educational experiences of the faculty themselves. Frequent responses related their teaching approach to the ways in which they experienced engineering education at various points in their career. Faculty reported the overwhelming style of instruction in their own education was traditional, lecture style with a small percentage reporting some hands-on activities and projects. Typically, the PEL projects followed the model suggested by ${ }^{1}$ and included a semester-long supplemental assignment that attempted to provide an authentic application of course concepts.

Overwhelmingly, $88 \%$ of survey respondents, engineering faculty expressed interest in alternative teaching methods. However, $75 \%$ noted concerns about the time to construct and assess PEL projects given the constraints of research-intensive campuses. Faculty report that "best practices" of implementing PEL projects include providing time for project development, advance notice for students to ensure clear expectations, and that projects designed to be semester long should include a variety of course concepts. One faculty member suggests that it is best to assign the project early in the semester "so that they can get thinking on a concrete example[s]." This additional time allows student groups to review the project concept several times as a group and turn to instructors throughout the semester for clarity. Due to the assessment weight and the length of the project, student project groups are often strategically composed to provide an intellectual balance. Instructors also hope to encourage peer-to-peer instruction, socialization, and added camaraderie. However one instructor commented that his approach to assigning teams varies. Commenting on issues that face PEL he states: "some of the issues of course have to do [with the fact that] whenever you have a team project [you have the issue] as to how you form the teams and whether a student likes their partner...I let them choose their own partner, but [I] put some constraints on that because I wanted to make sure that the teams would not [be] very unbalanced in the [intellectual] composition..."

During the project, it was observed that the availability of model projects, documentation, and material resources were influential in convincing some instructors to adopt PEL. In some cases, instructors who initially resisted adopting PEL changed to a favorable disposition after 
interacting with students and faculty who were favorable. This indicates that unfamiliarity with PEL and the absence of model projects or other materials may represent a significant barrier to adoption. Conversely, availability of materials, project models, and instructor role models may offer the best opportunities for breakthrough to widespread practice of PEL.

\section{B. How does the implementation of PEL in gateway engineering classrooms follow "best practice" as identified by the research?}

Faculty who attempted PEL perceive significant benefit to implementing PEL in engineering education and cites increased student motivation as the most significant outcome. One participate noted the dual nature of benefit to students "the benefit is that students will have an immediate application of the theory that they are learning-something that is quantifiable [and] something that is physical and that they can relate to." Succinctly put, one faculty member states that PEL provides "an immediate application of the theory that they are learning."

Over $75 \%$ of survey respondents report the likely benefits of PEL in engineering education include positive or strongly positive effects in students' understanding of important engineering concepts; students' ability to apply or generalize skills and concepts to other areas of science and/or real-life situations; students' self-confidence in doing science; and, students' interest in the discipline of engineering.

Interestingly, faculty reported that increased contact between instructor and student as an unanticipated positive outcome as an increased number of students attended office hours and engaged faculty outside of class. One subject recalled that time spent processing the project prompted students to "come and discuss the project with me when they're having difficulties [or] when they have questions and I have office hours outside the classroom, but I always make sure that if they [can't] come at that time that I was available to discuss any questions they had on the project." Faculty reported that these interactions expanded beyond the assignment and provided an opportunity for professional mentoring and socialization to the life of an engineer. This increased sense of community follows the research that suggests a positive relationship with retention and degree completion efforts.

It appears that faculty tends to retain their lecturing on hierarchical content knowledge and deductive reasoning in engineering science, while relying on PEL for motivation, interaction, and application learning. This is consistent with best practices reported in the research on PEL and related pedagogical approaches.

\section{How supported (by all stakeholders) do instructors feel during the PEL implementation process?}

Faculty report that the support for active learning approaches including PEL is beginning at the campuses involved in this project. Respondents noted that while some of their colleagues may have no knowledge of PEL, they are generally supported to explore new and perhaps innovative instructional strategies. The time provided through the NSF grant to work together on the generation of projects and sharing of tips and techniques is seen as beneficial for faculty to adopt these practices. It would seem that creating further opportunities for faculty to collaborate would 
have positive impact on the level of implementation and the possibility of compiling a collection of projects across curricula could be advantageous.

\section{What are the challenges to implementing PEL in engineering classrooms?}

Faculty had strong feelings regarding the barriers to implementing PEL and other active learning strategies in engineering instruction. While it is clear there is an intention on the part of committed engineering instructors to use PEL to advance the curriculum, there is significant concern that its adoption not be used to the detriment of the content instruction or student growth. PEL, as one instructor states, can be used to fool students into thinking that engineering is "fun" or likened to a science fair that ultimately waters down foundational concepts. Conversely, one participant noted that "the project should not be burdened with a lot of additional busy work that might actually be realistic in terms of what an engineer has to do in a real project, but is not helpful in the learning process," Here the point is made that there needs to be a balance between the authentic tasks of engineers and the larger conceptual goals of the course. Faculty members see the projects as helping students bridge concepts built around mathematical equations to real life applications in the field. It was also suggested that projects can also be used after the course as a way to enhance a student's resume or demonstrate knowledge during job interviews.

Obstacles to implementation can include an instructor's level of comfort with the project's purpose in the course (i.e. they will not have a project just to have a project or for the sake of saying they are practicing PEL) and the time required for faculty to create and assess projects in a research-intensive university. Faculty reported some concern with the level of student comfort or prior experience with PEL or active learning approaches as it is possible that some students prefer a more traditional instructional approach. As some courses are shared enrollment with other subfields in science education (i.e. students from various fields outside of engineering), one instructor reported sacrificing or adjusting a project in order to meet the needs of class as a whole, rather than just a portion.

Although instructors who declined to attempt PEL were not interviewed formally, some reasons given for declining are noted: (a) The class size is too large, and the burden of grading a large number of projects is unacceptable; (b) The effort to create a meaningful project is beyond what a tenure-track instructor can accomplish, given pressing research goals; lack of accessible lab time for projects; and (d) The best way for students to learn difficult engineering science fundamentals is to work hard on more homework problems. We note that a small percentage of survey responses (11-12\%) were consistently negative about the efficacy of PEL in the engineering classroom. There also appear to be interesting differences between the concerns of experienced, perhaps more conservative, instructors, and younger, novice faculty members. We may generalize from these observations that an incremental approach to introduce PEL that also anticipates these perceived barriers may in the long term lead to more successful transformation of the student's learning success in gateway courses in the engineering curriculum.

Additionally, survey respondents made clear distinctions in the differences between how they were taught, the way they teach, and PEL. All respondents indicated in an open-ended item that they received the majority of their undergraduate engineering training via traditional lectures. 
Yet $88.9 \%$ of the instructors agreed or strongly agreed that they were comfortable using projectbased methods, and $87.5 \%$ of respondents affirmed interest in alternative instructional strategies for engineering programs. These distinctions point to a potential problem in that respondents may not be clear in their understanding of the definition of PEL. In other words, if they see PEL as clearly distinct from their own practice, it might point to a failure to understand how PEL is meant to enhance their own practice, not replace it.

For the purposes of this paper, we categorize limitations to the implementation of PEL as either internal or external. Internal limitations, such as personal teaching preference, negative perceptions of PEL or willingness to learn new techniques, were almost nonexistent. For the most part, respondents reacted favorably to new teaching methods, expressed openness to changing their own practice, and felt well-supported in the PEL implementation process. When respondents mentioned limitations they were external in nature - i.e., time, students' abilities, or expectations from the engineering profession in terms of students' readiness for work. Of these limitations, time seemed to be a major issue. Based on survey results, there appears to be a conflict between the implementation of PEL and the time allotted to instructors to complete the required tasks of a faculty member at a major research institution (such as research for publications, teaching, and service): $75 \%$ of respondents indicated having concerns about the time required for faculty to create and assess active learning exercises in a research-intensive university environment. Further impacting the time issue, many instructors found it necessary to create their own PEL materials (50\% of respondents) or add to already existing materials $(62.5 \%$ of respondents). However, within the broad category of time there are many different interpretations that require clarification. It is unclear if respondents were mainly concerned with their own time restraints in terms of their job expectations and requirements or time constraints in terms of class time and overall length of the degreed program.

\section{Conclusions}

There is growing and welcome attention to the retention of engineering students and the impact of new instructional strategies. As an on-going study of faculty perceptions of project-enhanced learning in early engineering education, the results reported in this paper connect to the wellresearched and demonstrated benefits of active learning strategies in engineering education, including the use of projects. Project-enhanced learning (PEL) represents a carefully calibrated approach to active learning using projects that seeks to retain and enhance traditional lecturebased teaching that many instructors view as necessary or indispensable. Although similar to PBL in providing an inductive learning experience, it is intended to complement rather than replace the necessary deductive learning in such courses, and to support integrative thinking and student motivation.

While the small sample size prohibits meaningful statistical analysis of the survey data, there are some generalizable themes based on both the closed and open-ended questions. Respondents, with one outlying exception, had positive feelings towards PEL. Respondents felt that using PEL was worthwhile and beneficial to their students. When asked to provide an overall assessment of the likely effect of the PEL initiative in terms of student outcomes, aside from the one consistent outlier (who indicated a strongly negative effect for each item), respondents felt PEL would likely have a positive or strongly positive effect; these items included students' understanding of important engineering concepts, their ability to apply or generalize skills and concepts to other 
areas of science/other disciplines/real-life situations, students' self-confidence in doing science, and students' interest in and/or appreciation for the discipline.

Instructors who agreed to attempt PEL expressed satisfaction with student learning outcomes, despite reservations about workload and potential dilution of academic rigor. They were particularly impressed with increased student motivation and with the immediacy of application provided by the project, as well as the socialization of students into the community and culture of engineering. They also noted the increased interaction of students with each other and with instructors. Most students has expressed satisfaction with their project experience, but some were not pleased with the additional workload.

Instructors expressed concern about misleading students about the challenges and rigor of engineering education by focusing on the project perhaps at the expense of more analytical tasks essential to the course topics. Committed instructors achieved a balance between project benefits and course goals by designing project tasks to closely align with specific learning outcomes of the course, and whittling down less relevant activity. While expressing some concern about losing focus on the challenging analytical topics, instructors achieved appropriate balance by designing project tasks to align well with most topics. Interaction with other instructors using PEL and with students helped instructors overcome initial reservations. A few instructors responded to the survey with a strong negative view of PEL. It is possible that instructors who expressed no interest in PEL and did not respond to the survey request may also have an unfavorable disposition.

Support from an NSF grant allowed instructors some time for creation of projects and preparation for teaching. For some instructors, PEL materials were already available and had been used in their course previously. Using ETMM to study PEL perceptions, utilizing multiple scholarly sources and research approaches over a long-term time-line, allowed the research team to delve deeply into multiple facets of PEL. Insight provided in this research embarks on a discovery on not only how pedagogical practices in engineering influences student learning, but how administering it impacts the professoriate. This study does not investigate whether instructors would attempt PEL without such assistance. This study has also not examined the thinking of instructors who either ignored the PEL activity or specifically declined to attempt PEL. These questions would be fruitful areas for future research.

This paper points to several conclusions about PEL and faculty implementation. As an active learning approach, PEL provides increased opportunity for faculty/student interaction and enhances traditional lecture-based instruction with authentic application of engineering concepts. Faculty report positive increases in student motivation, socialization to the field, and learning outcomes as a result of PEL implementation. Faculty satisfaction was a direct result from intentional project design that incorporated specific learning outcomes within courses and minimized "busy work." While the need for more research is clear, this project suggests that the positive impacts of PEL may go well beyond course enrollment numbers by increasing engineering faculty and student satisfaction and broadening instruction experiences in engaging ways. 


\section{References}

1. S. Krishnan and M. R. Nalim, "Project based Learning in Introductory Thermodynamics," Proceedings of the 116th American Society of Engineering Education Annual Conference, Austin, TX. Paper AC 2009- 1911, 2009.

2. R. Nalim, L. Li, P. Orono, R. Helfenbein, W. Yu, M. Mital, "Project-Enhanced Learning in Challenging Engineering Science Courses," ASEE Illinois/Indiana 2012 Section Conference, 2012.

3. V. Tinto, "Leaving college: Rethinking the causes and cures of student attrition," Chicago: The University of Chicago Press, 1993.

4. W.G. Bowen, M.M. Chingos, and M.S. McPherson. Crossing the Finish Line: Completing College at America's Public Universities. Princeton, NJ: Princeton University Press, 2009.

5. J. M. Braxton, J. F. Milem, A. S. Sullivan, "The Influence of Active Learning on the College Student Departure Process," The Journal of Higher Education, vol. 71: 5, pp. 569-590, 2000.

6. J. A. Anderson, and M. Adams, "Acknowledging the learning styles of diverse student populations: Implications for instructional design. In L. L. B. Border and N. Van Note Chism (Eds.), Teaching for diversity. No. 49: New directions for teaching and learning, pp. 19-33, San Francisco: Jossey-Bass, 1992.

7. A. W. Chickering, and Z. F.Gamson, "Seven Principles For Good Practice In Undergraduate Education," AAHE Bulletin, pp. 3-7, 1987.

8. D. W. Johnson, R. T. Johnson, and K. A. Smith, "Cooperative Learning: Increasing College Faculty Instructional Productivity,” ASHE-FRIC Higher Education Report No. 4. Washington, D.C.: School of Education and Human Development, George Washington University, 1991.

9. W. McKeachie, P. Pintrich, L. Yi-Guang, and D. Smith, "Teaching and Learning in the College Classroom: A Review of the Research Literature", Ann Arbor: Regents of the University of Michigan, 1986.

10. J. F. Milem, J. B. Berger, "A modified model of college student persistence: Exploring the relationship between Astin's theory of involvement and Tinto's theory of student departure”. Journal of College Student Development, vol. 38, pp. 387-400, 1997.

11. R. M. Felder, R. Brent, T. K. Miller, C. E. Brawner, R. H. Allen, "Faculty Teaching Practices and Perceptions of Institutional Attitudes Toward Teaching at Eight Engineering Schools," ASEE FIE Conference, Session T1G, 101-105, 1998.

12. C. Hsieh, and L. Knight, "Problem-based learning for engineering students: An evidence-based comparative study". The Journal of Academic Librarianship, vol. 34: 1, pp. 25-30, 2008.

13. P. T. Terenzini, A. F. Cabrera, C. L. Colbeck, J. M. Parente, and S. A. Bjorklund, "Collaborative learning vs. lecture/discussion: Students' reported learning gains. Journal of Engineering Education, vol. 90: 1, pp. 123-130, 2001.

14. J. Dutton, M. Dutton, and J. Perry, "Do online students perform as well as lecture students?," Journal of Engineering Education, pp. 131-136, 2001.

15. S. D. Sheppard, K. Macatangay, A. Colby, and W. M. Sullivan. "Educating Engineers: Designing for the Future of the Field," The Carnegie Foundation for the Advancement of Teaching Series, Jossey-Boss Publications, San Francisco, CA, 2008.

16. J. Meyer, N. Lamm, and J. Smith, "Retaining freshman engineering students through participation in a first-year learning community: What works and what doesn't.," American Society for Engineering Education. 2007.

17. P. Cawley, A problem-based module in mechanical engineering In D. Boud and G. Feletti (Eds.), The Challenge of Problem Based Learning London: Kogan Page. pp. 177-185, 1991.

18. I. Denayer, K.Thaels, J. V. Sloten, and R. Gobin, “ Teaching a structured approach to the design process for undergraduate engineering students by problem-based education," European Journal of Engineering Education, vol. 28: 2, pp. 203-214, 2003.

19. D. R. Woods, "Problem-based learning for large classes in chemical engineering. In L. A. Wilkerson and W. H. Gijselaers (Eds.), Bringing Problem-based Learning to Higher Education: Theory and Practice, pp. 91-99. San Francisco, CA: Jossey-Bass, 1996.

20. J. C. Perrenet, P. A. J. Bouhuijs, and J. G. M. M. Smits, "The Suitability of Problem-based Learning for Engineering Education: theory and practice," Teaching in Higher Education, vol. 3:5, pp. 345 - 358, 2000.

21. Dym, C. L., Agogino, A. M., Eris, O., Frey, D. D. and Leifer, L. J. (2005), Engineering Design Thinking, Teaching, and Learning. Journal of Engineering Education, 94: 103-120. 
22. Frank, M., Lavy, I., \& Elata, D. (2003). Implementing the project-based learning approach in an academic engineering course. International Journal of Technology and Design Education, 13(3), 273-288.

23. L.F. Johnson, R. S. Smith, J.T. Smythe, and R. K. Varon, Challenge-Based Learning: An Approach for Our Time. Austin, Texas: The New Media Consortium, 2009.

24. J. E. Mills, and D. F. Treagust, "Engineering education - Is problem-based or project-based learning the answer? ," Australasian Journal of Engineering Education, pp. 1-16, 2003.

25. L. R. Barroso, and J. R. Morgan, "Project enhanced learning: Addressing ABET outcomes and linking the curriculum," Journal of Professional Issues in Engineering Education and Practice, vol. 135: 1, pp. 11-20, 2009.

26. M. Chatterji, "Evidence on "what works": An argument for extended-term mixed method (ETMM) evaluation designs". Educational Researcher, vol. 33:9, pp. 3-13, 2004.

27. B. Glasser, "The constant comparative method of qualitative analysis," Social Problems, vol. 12:4, pp. 436-445, 1965.

28. J. W. Creswell, "Qualitative inquiry and research design: Choosing among five approaches," Thousand Oaks, CA, 2007.

29. P. F. Carspecken, "Critical ethnography in educational research: A theoretical and practical guide". New York and London: Routledge. 1996

30. K. A. Neuendorf, "The content analysis guidebook," Thousand Oaks, CA: Sage Publications, 2002.

31. B. G. Glaser, and A. L. Strauss, "The discovery of grounded theory: Strategies for qualitative research," Chicago: Aldine Publishing Company, 1967. 